\title{
Saber escolar e conhecimento histórico?
}

\author{
Maria Auxiliadora Schmidt
}

\section{RESUMO}

Se 0 ensino de História passa em silêncio ou quase, a luta do povo, suas tradições, seus conflitos, seus momentos de glória e de dor, como pode se esperar que ele lhe possa dizer respeito? 0 povo quer transmitir sua herança histórica, a lembrança da opressão e os momentos cruciais nos quais ele foi ator, onde ele traçou um caminho em direção a uma sociedade nova. (Georges Snyders)

A problematização do título deste trabalho tem como referência uma perspectiva dialógica e relacional entre dois conceitos que se opõem sem se excluir: saber e conhecimento.

Em primeira instância, este diálogo remete aos significados que lhe são auferidos pela própria língua portuguesa, na qual, saber significa "ter conhecimentos técnicos e especiais relativos a, ou próprios para", e conhecimento diz respeito à "apropriação do objeto pelo pensamento, como quer que se conceba essa apropriação: como definição, como percepção clara, apreensão completa, análise, variando o grau de passividade ou de atividade que se admitam na posição do pensamento em relação ao objeto" (Novo Aurélio, 1999). Neste caso, a natureza do saber histórico escolar teria um componente mais utilitário, que o colocaria em oposição ao conhecimento histórico, de outra natureza.

Este diálogo remete, também, à recuperação de uma discussão que vem acompanhando o debate recente acerca do ensino de História no Brasil, desde a proposição dos Parâmetros Curriculares Nacionais pelo Ministério da Educação. (1997;1998). Ao distinguir tipos de conteúdos históricos: conceituais, procedimentais e atitudinais, estes Parâmetros recorrem à idéia do "saber

\footnotetext{
* Profa. e pesquisadora do Programa de Pós-Graduação em Educação da Universidade Federal do Paraná, Linha de Pesquisa Cultura, Escola e Ensino. Profa. de Metodologia e Prática de Ensino de História da UFPR.
} 
histórico" utilizável, onde o "saber usar" é a medida e referência para 0 conhecimento, o qual estaria sempre relacionado ao desenvolvimento de competências (atitudinais, procedimentais, conceituais), além de vinculado aos sistemas e demandas do atual desenvolvimento tecnológico. Neste sentido, o saber histórico escolar seria um entre os outros "saberes" de natureza prática, necessários e imprescindíveis para se viver e sobreviver na era da globalização.

Em outro patamar, o diálogo perpassa as discussões que vêm sendo encetadas no âmbito da didática das disciplinas, nomeadamente os estudos relativos à transposição didática (CHEVALLARD, 1991; DEVELAY, 1992; MONIOT, 2001), ao conceito de mediação didática (LOPES, 1999) e interpelação didática (MONTEIRO, 2002). Em seu conjunto, estes trabalhos remetem para o debate acerca da especificidade do conhecimento escolar em relação ao da ciência de referência e têm como perspectiva de análise os estudos realizados no âmbito da língua francesa, na qual há reciprocidade entre o significado da palavra saber, tanto para designar o "saber ensinado", isto é, o conhecimento escolar, como o "saber sábio",ou seja, o conhecimento das ciências de referência. Neste sentido, conhecimento histórico e saber escolar são faces da mesma questão, a qual diz respeito, principalmente, às relações entre o significado da História como ciência e seus usos no processo de escolarização, constituindo o que Cuesta $(1998 ; 1997)$ chamou de construção do código disciplinar da História. Este autor parte dos estudos de Foucault e Ludgren, indicando dois elementos basilares na construção do código disciplinar da História: os textos visíveis (currículos, manuais didáticos etc) e os textos invisíveis (as práticas escolares, as concepções de história de alunos e professores). Ademais, conforme aponta Cuesta, importa que tantos os textos visíveis como os invisíveis, sejam compreendidos a partir do contexto histórico, dos modos de educar e das relações de poder onde estão inseridos.

No Brasil, o discurso histórico acerca do código disciplinar da História aponta vários momentos de crise da relação entre o conhecimento histórico escolar e a ciência de referência. Já no final do século XIX, no prefácio ao manual didático História do Brasil, de João Ribeiro, Araripe Junior, recém chegado da Alemanha onde havia acompanhado as inovações no ensino de História, afirma um momento de crise da relação entre o conhecimento escolar e o conhecimento histórico, manfestada na insuficiência do método de ensino 
para dar conta do desenvolvimento cognitivo dos alunos individualmente. Ele expõe a necessidade de uma reforma metodológica deste ensino no Brasil, defendendo que "o méthodo é a maravilha da escola e a delícia do professor". A crise do método é também objeto de reflexão, em 1935, por parte de dois professores preocupados com a relação entre o como e o que ensinar na História. São eles Jonathas Serrano e Murillo Mendes. 0 primeiro foi professor de cursos de formação de professores, membro do Instituto Histórico e Geográfico Brasileiro, autor de inúmeros manuais didáticos para alunos e professores de História. Ele chegou a constatar a existência de uma crise do método de ensino de História, o qual era baseado na memorização das exposições orais e dos pontos escritos adaptados da ciência de referência, sugerindo uma ampla renovação metodológica do ensino, principalmente devido às transformações tecnológicas (como a invenção do cinematógrafo escolar), propondo, também, a "urgente necessidade de applicar ao ensino da História todas as conquistas reaes da psycho-pedagogia e da didactica renovada"(1935, p.13). 0 segundo, que também se dedicou à formação de professores de História, autor de um clássico estudo sobre o ensino de história na escola secundária, registrou a sua preocupação com o descaso que via entre os jovens de sua época, em relação ao conhecimento histórico e propôs uma renovação do conhecimento histórico escolar , que levasse em consideração a sua utilidade para a vida da juventude, utilidade esta que deveria

estar em funcção dos complexos problemas sociais que somos chamados a resolver e que exigem das novas gerações a apreciação de um mundo mais intelligível, em que possam mais efficazmente cooperar para a melhoria da vida collectiva, na tendência universal e irreprimivel da nova educação, a que o Brasil não poderáse esquivar (MENDES, 1935, p.15).

Nenhum desses autores fez críticas à concepção de conhecimento histórico difundido nas escolas , constatando apenas a existência de uma crise no "método de ensino" e na perspectiva por meio da qual os professores de História viam os seus alunos como sujeitos passivos da aprendizagem do conhecimento histórico. Tratase, como afirmam Carretero e Krieger (2004), do momento em que a relação entre a história e a escola se fundamenta e se legitima na confluência de duas dimensões constitutivas da educação estatal: a a lustrada-cognitiva, vinculada ao desenvolvimento 
cognitivo individual, e a romântica, de caráter emotivo nacionalista. Para estes autores, estas duas dimensões "continuam em tensão permanente até os nossos dias"(p.83). No entanto, nas primeiras décadas do século XX, no Brasil, observa-se uma agudização da crise deste aspecto do código disciplinar da História, principalmente devido à expansão do movimento reformista da Escola Nova, o qual acentuava a importância da renovação metodológica como pressuposto para 0 desenvolvimento cognitivo individual e este como um dos caminhos que levariam a escola a realizar seu objetivo messiânico de salvação da republica brasileira.

Assim como a natureza do conhecimento histórico, a natureza da escola não estava em questão neste momento. Dentro da mais pura tradição Durkeinniana, a escola era vista como uma instituição de natureza específica, diferente da educação familiar a qual era considerada por Emile Durkheim como "voluntária". Pioneiro na análise da relação escola/sociedade, este autor via a escola como uma instituição social com três funções principais: educação, seleção e socialização. Nesta escola, o objetivo principal era formar o aluno de certo tipo e a valorização do método tinha como finalidade adequar o projeto escolar à clientela, em diferentes momentos históricos.

Esta mesma tendência foi observada nos estudos realizados por Leite (1969), a partir de levantamentos sobre o ensino de História em diferentes escolas de São Paulo e Rio de Janeiro. Neste mesmo estudo, esta autora já anuncia a complexificação da relação entre o conhecimento histórico escolar e a ciência de referência pois, "A partir de 1960 vem-se propondo substituir o ensino de História e Geografia pelo de Estudos Sociais" (1969, p.10), o que sabemos, se concretizou com o Parecer 853 da Lei 5692/71, no auge do período da Ditadura Militar. Posteriormente, Nadai (1992), em estudo já clássico sobre a trajetória do ensino de História no Brasil, admitiu também a existência de uma crise do método de ensino nos moldes já apontados anteriormente,mas indicando uma crise na ciência de referência, como afirma

0 ensino de História vive atualmente uma conjuntura de crise, que é, seguramente, uma "crise da história historicista", resultante de descompassos existentes entre as múltiplas e diferenciadas demandas sociais e a incapacidade da instituição escolar em atende-las ou em responder afirmativamente, de maneira coerente, a elas. Crise que espelha as modificações da própria produção científica, que, de certa forma, ampliaram o leque de possibilidades do pensar, do fazer e do escrever a história"(p.144) 
$\mathrm{Na}$ esteira das discussões encetadas na época e de algumas proposições que vinham se consubstanciando sob a forma de propostas curriculares em vários sistemas estaduais de ensino, Nadai (1992) aponta a crise da concepção de história produzida no século XIX e indica o que seriam os elementos para uma relação qualitativamente diferente entre o conhecimento escolar e a ciência de referência, quais sejam:

a constataçã̃o da existência de um saber histórico escolar com uma especificidade e legitimidades próprias; o reconhecimento do fim do domínio das grandes narrativas históricas e 0 encaminhamento para outras concepçoes de narrativa como a história temática e a micro-história; a necessidade do ensino de história tomar como referencia o próprio método da ciência; a superação da dicotomia ensino-pesquisa e a busca por propostas pedagógicas que contemplassem a realidade social dos alunos e professores; a compreensao de que alunos e professores são sujeitos da História e desta como movimento social e enquanto memória; 0 uso escolar dos documentos históricos bem como a renovação da utilização destes nos manuais didáticos.

A constatação de elementos novos na crise da relação entre a história ensinada e a ciência de referencia ocorre no contexto onde repercutem as contribuições da sociologia e da filosofia da educação. Trabalhos como os de Pierre Bourdieu e Jean-Claude Passeron sobre a escola como reprodutora da ideologia dominante e da violência simbólica; as contribuições de Althusser sobre a escola como aparelho ideológico do Estado; de Gramsci, acerca da escola como aparelho privado de hegemonia, para citar alguns exemplos, abrem a possibilidade de se olhar a escola, não mais como instituição integradora, à moda de Durkheim, mas como reprodutora de práticas e desigualdades sociais e culturais.

Neste sentido,constitui-se um dilema no processo de escolarização e, portanto, no significado do conhecimento escolar, acirrado pela expansão e massificação da escola pública. Este dilema resultou em embates, como

- os que queriam a permanência da escola como instituição independente, formadora e construtora de cidadãos para a humanidade, a pátria e a comunidade; 
- aqueles que queriam uma escola mais realista, aberta ao mercado, útil e eficaz

De modo geral, pode-se afirmar que, a partir de meados da década de 1980 até o final da década de 1990, há um confronto de projetos que buscavam novos referenciais para a escola e o ensino de História. De um lado, projetos que acolheram perspectivas teóricas e metodológicas mais pertinentes à história dos movimentos sociais e do trabalho; de outro, projetos que sugeriam adoções de concepções metodológicas mais próximos à historiografia dos Annales. Este confronto está relacionado, sem dúvida, ao contexto em que a sociedade brasileira, recémsaída do período ditatorial, empreende a busca dos seus novos caminhos.

A construção dos Parâmetros Curriculares Nacionais, especificamente 0 de História pode ser visto como um dos momentos deste confronto, o qual já está antecipado no documento de análise das propostas curriculares para 0 ensino fundamental, produzido em conjunto pelo MEC/UNESCO e Fundação Carlos Chagas. (1995) Este documento foi construído com a finalidade de subsidiar a elaboração dos parâmetros curriculares nacionais para o ensino fundamental e baseia-se na análise das propostas elaboradas pelas Secretarias de Educação de vários Estados brasileiros, entre 1985/1995. Um dos pontos a serem destacados neste documento é a crítica que faz quanto às contradições entre os discursos predominantes nas propostas, o qual considera "bastante genérico" e incapaz de "auxiliar quanto às opções que devem ser feitas em relação a enfoques teóricos divergentes em determinado campo de conbecimento". Ademais, considera que o posicionamento das reformas em favor das classes populares não é suficiente porque não supre as deficiências do processo de reelaboração didática exigido pela transposição didática das respectivas disciplinas acadêmicas em saber escolar, afirmando que "trata-se de um discurso com clara conotação política que tem demonstrado contudo, no mais das vezes, frágil intersecção com as proposições dos especialistas que efetivamente tem conferido a tônica ao currículo".(MEC/ UNESCO/FCC,1995, p.6).

Pode-se observar nestas afirmações alguns dos pressupostos que norteariam a elaboração dos Parâmetros Curriculares Nacionais como um todo e, em particular, as diretrizes sugeridas para o ensino de História (MEC/ SEF,1998), onde se enfatiza o método de ensino e predominam aspectos 
multifacetados de concepções historiográficas, bem como a ênfase na concep̧̧ão de currículo elaborada por especialistas, pautada na perspectiva atitudinal e procedimental dos conteúdos, ou seja, na perspectiva da existência de um "saber escolar" originado de um processo de transposiçãa didática feito a partir da ciência de referencia. A pulverização dos conteúdos e a ênfase no método, características dos Parâmetros Curriculares, são fortes indícios de sua articulação com a pedagogia das competências, ou, como afirma Moraes, um "0 iluminismo às avessas", que se caracteriza, entre outros, pela pragmática retórica de ressignificação de conceitos, onde "uns foram naturalizados - o capitalismo, por exemplo -, alguns foram construídos, ressignificados, modificados ou substituídos por outros mais convenientes. 0 termo "igualdade, entre outros tantos exemplos, cedeu lugar à "equidade", o conceito de classe social foi substituído pelo de status socioeconômico, os de pobreza e riqueza pela peculiar denominação de baixo e alto ingresso social'(MORAES, 2003,p.158).

Torna-se relevante lembrar, ainda, a conjuntura político-econômica da produção dos Parâmetros Curriculares Nacionais, no contexto das políticas neoliberais e do projeto de globalização econômica ao qual foi inserido o Brasil , particularmente a partir da última década do século XX o que, em certa medida, impõe os limites da superação da crise educacional brasileira e do próprio ensino de História.

Assim, a relação entre o conhecimento histórico escolar e a ciência de referência, hoje, necessita ser pensada no contexto da própria crise do significado da escola e da educação em geral, e no Brasil em particular. Isto significa desvelar conceitos epistemológicos que afetam a teoria e a prática de ensino, tendo como referência o conhecimento histórico e também o conhecimento pedagógico, inseridos em relações de poder matizadas por questões como a reconceitualização do modelo de democracia, da lógica do projeto neoliberal e seu determinismo globalizador, da revolução tecnocientífica e da chamada "nova era do conhecimento". Mas, também, por fortes manifestações de culturas de resistências que tomam a experiência social como ponto de partida para pensar a escola e o significado do conhecimento escolar em sua relação com a ciência de referência.

Estas perspectivas, baseadas em trabalhos como os de Paulo Freire, François Dubet, Bernard Charlot e Michael Apple, buscam problematizar a equivalência 
entre a educação do sujeito e a sociedade na direção da emancipação e da democracia radical., impondo o desafio de buscar caminhos que conciliem a autonomia dos sujeitos com o caráter histórico e determinado da transformação social. A escola como espaço público da experiência social não é aqui definida apenas pela tensão entre a comunidade e o mercado, por exemplo, pela oposição entre as nações e 0 capitalismo internacional, as religiões e a racionalidade, (educar para Deus, para a pátria, para a razão, para o mercado?). A escola é como um espaço vinculado diretamente à ação política, relacionado à possibilidade e à intencionalidade da construção coletiva de um projeto político para a educação do sujeito e 0 desenvolvimento da cidadania transformadora.

Neste sentido, é que se afirma ter o conhecimento histórico escolar uma natureza própria e uma especificidade, tendo em vista sua relação orgânica com a educação e construção da autonomia dos sujeitos no contexto da democracia social. Assim, trata-se de um conhecimento que nunca poderá ser outorgado pelo Estado, apesar de que este deverá garanti-lo, respeita-lo e defende-lo pois, antes que um outorgamento, ele precisa ser uma conquista cívica frente ao poder do Estado.

Isto significa tomar como perspectiva a idéia da construção social da relação entre o conhecimento histórico escolar e a ciência de referência, pensando-o como um trabalho coletivo, realizado a partir e além das experiências dos sujeitos (crianças, jovens, professores e professoras), inserido no próprio movimento histórico de amplo alcance, mas com suas peculiaridades e particularidades locais pois, cada uma das experiências pode ser demonstrativa das diferentes lutas sociais. As diferenças regionais, as organizações sociais e sindicais, a lutas dos professores, as diferenças sociais e étnicas, bem como 0 peso das igrejas precisam deixar suas marcas na origem e na vivência do conhecimento histórico escolar. Estes constituem a trama real em que se realiza a educação e, portanto, a educação histórica que somente se concretiza na e a partir da relação que os sujeitos estabelecem com o conhecimento da ciência de referência numa "trama em permanente construção que articula histórias locais - pessoais e coletivas -, diante das quais a vontade estatal abstrata pode ser assumida ou ignorada, mascarada ou recriada, em particular abrindo espaços variáveis a uma maior ou menor possibilidade hegemônica" (ROCKWELL/EXPELETA, 1989, p.12). 
A construção desta trama requer uma relação entre conhecimento histórico escolar e a ciência de referencia, centrado na concepção dos homens como sujeitos sociais, vivendo e reproduzindo-se no modo histórico particular do mundo real, cujas práticas individuais inscrevem-se simultaneamente em diferentes práticas coletivas e níveis de "integração"de cada formação social. Assim, na escala das integrações maiores, o conteúdo de certas práticas tornase mais ou menos relevante para se compreender e agir no sentido da reprodução ou da transformação das relações sociais hegemônicas. Por exemplo,é importante levar em consideração que o estudo da história política e econômica onde se pode apreender a existência do movimento social, só terá relevância se inserido nos âmbitos próximos da vida cotidiana onde se pode descobrir, por exemplo, aspectos não documentados deste movimento.

0 processo de construção social do conhecimento histórico escolar pressupõe "uma teoria do perigo" à moda da filosofia da História, de Walter Benjamin, a qual contrapõe-se a posições tradicionais, nas quais se fala da História como o que realmente aconteceu, como um processo transcendental, uma espécie de drama universal que se desenrola cronologicamente ao longo do tempo, onde as grandes narrativas históricas da evolução da humanidade assumem destaque.

A "teoria do perigo" pode servir para destacar a pluralidade, a divergência e a ambivalência como constitutivos da racionalidade histórica, de modo a tornar transparentes e cognoscíveis as ausências, lacunas e negações de sentido nos conteúdos do conhecimento histórico escolar, que revelam determinadas interpretações do passado vivido como experiência, pois, do contrário, o ensino de história teria um sentido nele mesmo, como uma história fechada e, portanto, mentirosa (RÜSEN, 2001).

0 perigo que nos ronda pode ser a dificuldade que estamos tendo em adjetivar o significado da escola e, portanto do conhecimento histórico escolar, de modo a fazê-lo contribuir para atuar sobre "as determinações de sentido do agir, dota-lo da capacidade de durar e de resistir na experiência possivel da "falta de sentido" (RÜSEN, 2001, p.173). Isto significa tomar a experiência como categoria mediadora entre a condição e a consciência dos sujeitos, articulando-a com os superávits de sentido do agir humano viabilizadores da utopia revolucionária. Neste sentido, pode-se conferir ao princípio da diferença, 
da pluralidade e da particularidade uma energia impulsionadora nas interpretações do passado, que o conhecimento histórico escolar, baseado na universalidade do desenvolvimento da humanidade, na identidade coerente e na efetividade de determinadas idéias de sentido, como a idéia de progresso, por exemplo, não dispunha.

Desse ponto de vista, a perspectiva da construção social do ensino de História não pode furtar a levar em consideração perguntas como "para que serve o ensino de História? Por que trabalhar a História na escola? Que significado tem a História para crianças e jovens? Que sentido tem a História para os professores?

A resposta a estas indagações pode ser encontrada, por exemplo, nas vertentes historiográficas que entendem a História como o estudo da experiência humana no tempo (THOMPSON, 1981), levando à compreensão de que a História estuda a vida de todos os homens e mulheres, com a preocupação de recuperar os sentidos ou a negação dos sentidos de sua experiência individual e coletiva. Este pode ser um dos principais critérios para a seleção de conteúdos e sua organização em temas a serem ensinados e cujo objetivo principal é contribuir para a formaçã̃o da consciência histórica numa perspectiva crítica e transformadora

Segundo Freire (1970), na formação da consciência crítica é necessário que a injustiça se torne um percebido claro na consciência, possibilitando aos sujeitos inserirem-se no processo histórico e fazendo com que eles se inscrevam na busca de sua afirmação. Ademais, afirma 0 autor, a consciência crítica possibilita a inscrição dos sujeitos na realidade para melhor conhece-la e transforma-la, formando-o para enfrentar, ouvir e desvelar o mundo, procurando o encontro com o outro, estabelecendo o diálogo do qual resulta 0 conhecimento: "os homens, desafiados pela dramaticidade da hora atual, se propõem a si mesmos como problema. Descobrem que sabem pouco de si [...] e fazem problema deles mesmos. Indagam. Respondem, e suas respostas os levam a novas perguntas" (1970, p.29).

Na esteira das questões já apontadas, pode-se afirmar, por exemplo, que um princípio articulador a ser incorporado na relação entre o conhecimento histórico escolar e a ciência de referência, é aquele que torna necessário que professores e alunos busquem a renovação dos conteúdos, a construção de problematizações históricas, a apreensão de várias histórias lidas a partir de 
distintos sujeitos históricos, das histórias silenciadas, histórias que não tiveram acesso à História. Assim, toma-se como propósito buscar a recuperação das vivências pessoais e coletivas dos alunos e professores, vendo-os como participantes na ação e no sofrimento, em determinada realidade histórica, a qual deve ser analisada e retrabalhada, com o objetivo de converte-la em conhecimento histórico, em auto-conhecimento, uma vez que, desta maneira, os sujeitos poderão inserir-se a partir de um pertencimento, numa ordem de vivencias múltiplas e contrapostas na unidade e diversidade do real.

Numa perspectiva teórica, ou seja, referindo-se às condições, finalidades e objetivos do ensino de História, a renovação metodológica, ou seja, um dos elementos constitutivos do conhecimento histórico escolar, necessita ser pensada a partir do significado, por exemplo, que os documentos possuem para os próprios sujeitos. Esta ordem de argumento dá ênfase à escolha de documentos que permitam seja colocada em discussão a formação da consciência histórica dos alunos e professores o que, segundo Rüsen (1992, p.28), é "um prérequisito para a orientação em uma situação presente que demanda ação". Isto significa que a consciência histórica funciona como um "modo específico de orientação" nas situações reais da vida presente, tendo como função específica ajudar a compreender a realidade passada para a orientação no presente e a intencionalidade no futuro.

Deste ponto de vista, a consciência histórica dá à vida uma "concepção do curso do tempo", trata do passado como experiência e "revela o tecido da mudança temporal no qual estão amarradas as nossas vidas, bem como as experiências futuras para as quais se dirigem as mudanças"(RÜSEN, 1992, p.29). Essa concepção molda os valores morais a um "corpo temporal", transformando esses valores em "totalidades temporais", isto é, recupera a historicidade dos valores e a possibilidade dos sujeitos problematizarem a si próprios e procurarem respostas nas relações entre passado/presente/futuro. Essa possibilidade, como afirma Freire (1970), pode ser indicativa do reconhecimento da desumanização como realidade ontológica e histórica, e também pode levar à pergunta se a humanização é possível.

$\mathrm{Na}$ esteira destes autores, a consciência histórica relaciona "ser"(identidade) e "dever"(ação) em narrativas significativas que tomam os acontecimentos do passado com o objetivo de dar identidade aos sujeitos a 
partir de suas experiências individuais e coletivas, e de tornar inteligível 0 presente, conferindo uma expectativa futura a essa atividade atual. 0 trabalho de construção dessa relação é uma das mais difíceis tarefas na articulação da relação entre o conhecimento histórico escolar e a ciência de referência,partiicularmente porque o conhecimento histórico veiculado no e pelos manuais didáticos é, como aponta Chevallard (1991), um conhecimento impessoal, anônimo e desvinculado da prática social. É importante que alunos e professores, partícipes na construção social desta articulação, desenvolvam a capacidade de identificar os indícios (conteúdos) da experiência humana, em diferentes formas, como na realidade cotidiana, na tradição, na memória de seus familiares, nos grupos de convívio. Ademais, é necessário compreender que a experiência humana apreendida nessa perspectiva indiciária, não possui apenas uma dimensão localizada, mas identifica-se com outras experiências de outras pessoas e outras épocas, podendo constituir-se sob a forma de diferentes narrativas históricas.

A construção social, portanto coletiva, da relação entre o conhecimento histórico escolar e a ciência de referência pressupõe, então, novas formas de captação e didatização dos conteúdos a serem ensinados que têm como objetivo o desenvolvimento da consciência histórica crítico-genética, a qual supera mas não exclui formas tradicionais de consciência histórica. A perspectiva critica e genética se aproxima do que o educador Paulo Freire define como a passagem da consciência ingênua para a consciência crítica. Para o autor, esse processo não implica que o educador e o educando, em determinado estágio de aprendizado,entendam todo o significado das palavras e conceitos, mas que tenham possibilidades de explicitar as mudanças em sua compreensão do mundo, ou seja, dado à natureza pública do conhecimento histórico escolar, é importante conhecer e levar em consideração os modos como os sujeitos se relacionam com o conhecimento histórico, tendo em vista torna-lo uma ferramenta de emancipação e não de submissão.

Os elementos constitutivos do processo de construção social da relação entre o conhecimento histórico escolar e a ciência de referencia apontam para o fato de que a construção da consciência histórica exige conteúdos que permitam o desenvolvimento de argumentações históricas críticas, de uma contra narrativa, na medida em que tais conteúdos buscam a mobilização, não de todo o passado, mas de experiências específicas do passado, relacionadas 
às próprias experiências dos sujeitos que não têm como objetivo 0 desenvolvimento cognitivo individual, mas na perspectiva de que os sujeitos envolvidos no processo ensino-aprendizagem se auto assumem em sua determinação histórica e cultural. A partir do seu presente e de sua experiência, crianças, jovens e professores se apropriam da ciência de referência como uma ferramenta com a qual podem romper, destruir e decifrar a linearidade de determinadas narrativas históricas, fazendo com que elas percam 0 seu poder como fonte única de compreensao do presente e de orientação para o futuro.

É necessário romper com a teoria histórica do perigo e despojar a mudança temporal do seu aspecto ameaçador, transformando-a no caminho em que estão abertas as opções para que a atividade humana crie um novo mundo, fazendo com que o futuro supere o passado em seu direito sobre 0 presente. Entende-se que somente a construção social da relação entre o conhecimento histórico escolar e a ciência de referencia pode criar condições que levam em consideração o compromisso inabalável com a relevância do conhecimento histórico, com as formas do conhecimento histórico ensinado, com a natureza do conhecimento histórico aprendido os quais, além de transformarem 0 ensino, superem a crise e transformem a própria escola pois, como afirma Snyders (1988), "no âmago, toda escola define-se pelos conteúdos que seleciona, propõe, privilegia - os que ela silencia, e é daí que decorrem as abordagens correspondentes, porque é o que define o tipo do homem que se espera ver sair da escola".

\section{Referências}

BONAFÉ, J. M. Esfera pública, conocimiento escolar y didáctica crítica. In.Revista Conciencia social.Didáctica crítica y escuela como espacio publico. Sevilha: Díada Editora, n.8, 2004, p.51-81.

BRASIL, Secretaria de Educação Fundamental. Parâmetros Curriculares Nacionais: bistória. Brasília: MEC/SEF, 1998.

CARRETERO, M.; KRIEGER, M. Forjar patriotas o educar cosmopolitas? El pasado y el presente de la historia escolar en un mundo global. In: CARRETERO, M. Voss; JAMES, F. Aprender y pensar la bistoria. Buenos Aires: Amorrortu, 2004, p.71-119. 
CHEVALLARD, Y. La transposición didáctica: del saber sabio al saber a ser ensinado. Argentina: Aique Grupo Editor S.A., 1997.

CUESTA FERNANDEZ, R. Clio em las aulas.Madrid: Akal, 1998.

. Sociogenesis de una disciplina escolar: a História. Barcelona: Ediciones Pomares-Corredor, 1997.

DEVELAY, M. De l'apprentissage à l'enseignement. Pour une epistemologie scolaire. Paris: ESF, 1999.

EZPELETA, J.; ROCKWELL, E. Pesquisa Participante. São Paulo: Cortez/Autores Associados, 1989 .

FREIRE, P. Educação como prática da liberdade. Rio de Janeiro: Paz e Terra, 1967. .Pedagogia do oprimido. Rio de Janeiro: Paz e Terra, 1970 . Pedagogia da Esperança: um reencontro com a Pedagogia do Oprimido. São Paulo: Paz e Terra, 1992.

LEITE, M. M. O ensino da Historia. No primário e no ginásio. São Paulo:Cultrix, 1969.

LOPES, A. Conbecimento escolar: ciência e cotidiano. Rio de Janeiro: UERJ, 1999.

MEC/UNESCO/FCC. As propostas curriculares oficiais. Análise das propostas curriculares dos estados e de alguns municípios das capitais para o ensino fundamental. Subsídios para a elaboração dos parâmetros curriculares nacionais. Mec/Unesco/Fundação Carlos Chagas, 1995.

MENDES, M. A bistória no curso secundário. São Paulo: Graphica Paulista, 1935.

MORAES, M. C. M. de. Iluminismo às avessas. Produção de conbecimento e políticas de formação docente. Rio de Janeiro: D \& A, 2003.

MONIOT, H. La question de la référence en didactique de l'histoire. In: Didactique des disciplines. Les references au savoir. Bruxelles: De Boeck \& Larcier, 2001, p.65-75.

- MONTEIRO, A. M. F. da C. Ensino de História: entre saberes e práticas. Tese de doutorado. Rio de Janeiro: PUC, 2002.

NADAI, E. O ensino de bistória no Brasil: trajetória e perspectiva. In. Revista Brasileira de História 25/26. Dossiê ensino de história. Memória, história, historiografia. São Paulo: Anpuh/Marco Zero/SCT/CNPQ/Finep, vol.13,n.25/26/set.92/agosto 93. 
RUSEN, J. El desarrollo de la competencia narrativa en el aprendizaje bistórico. Una bipótesis ontogenética relativa a la consciencia moral. Trad. Silvia Finocchio. Propuesta Educativa. Argentina. n.7. out/92.

- Razão bistórica. Teoria da bistória: os fundamentos da ciência bistórica. Trad. Estevão de Rezende Martins. Brasília: UNB, 2001.

SCHMIDT, M. A. Os parâmetros curriculares e a formação do professor: algumas reflexões. In. CAINELLI, M.; SCHMIDT, M.A. III Encontro Perspectiva do Ensino de História. Curitiba: Aos quatro ventos/UFPR, 1999.

SERRANO, J. Como se ensina a bistória. São Paulo:Comp. Melhoramentos, 1935.

SNYDERS, G. Alegria na escola. São Paulo: Manole, 1988.

THOMPSON, E.P. A miseria da teoria ou um planetário de erros. Uma crítica ao pensamento de Althusser. Rio de Janeiro: Zahar, 1981

VEIGA-NETO, A. Paradigmas? Cuidado com eles!. In: COSTA, M. V. Caminhos Investigativos. Rio de Janeiro: DP\& A, 2002. 